\title{
Estética del horror. Negatividad y representación después de Auschwitz
}

\author{
JOSÉ A. ZAMORA
}

Incluso el árbol que florece miente en el instante en el que se percibe su florecer sin la sombra del horror.

Th. W. Adorno

Desde un punto de vista general el problema de la representación de la negatividad extrema que refleja el nombre "Auschwitz" no se diferencia del de la representación de cualquier otro pasado histórico. Bastaría referirse al círculo hermenéutico en que está inscrita toda experiencia, a la imposibilidad de una experiencia no mediada por la interpretación de los acontecimientos o al indirimible conflicto de las interpretaciones, aspectos que no pueden dejar de tener reflejo en el plano de la representación, nunca a salvo de la deformación falsificadora o la armonización bien intencionada, pero no menos traicionera ${ }^{2}$.

Sin embargo, al plantear el problema de la representación de la catástrofe "Auschwitz" se está haciendo referencia a otras cuestiones que sobrepasan los mencionados supuestos ya habituales en la interpretación histórica y en la representación no sólo historiográfica, sino también estética de los acontecimientos de la historia. Dicho problema tiene que ver en primer lugar con la dimensión y la monstruosidad de ese acontecimiento histórico singular $^{3}$. El exterminio masivo de seres humanos organizado burocráticamente, dirigido administrativamente y ejecutado de modo industrial no sólo considerado en sí mismo, sino además por el hecho de que no puede ser visto como un mero "accidente", que tenga que ser visto como un punto culminante del desarrollo civilizatorio $^{4}$ que se ha producido en el ámbito cultural de una modernidad que reclama para sí el progreso, la Ilustración y una emancipación humana de repercusiones históricas mundiales, ha convertido a "Auschwitz" en una cesura que obliga a los medios convencionales de análisis racional a cuestionarse a sí mismos y a cuestionar la marcha histórica en la que pudo abrirse un abismo tan insondable de dolor e injusticia.

"Auschwitz" representa pues una quiebra en el proceso civilizador ${ }^{5}$ que exige un replanteamiento radical en la forma de considerar dicho proceso y prohíbe desde un punto de vista moral todo intento de asimilarlo a la "normalidad" histórica, sin que por ello deje de afectar a toda la historia y a nuestra visión de la misma ${ }^{6}$. Por otro lado, el espanto que produce "Auschwitz" está en pugna con el deseo legítimo de seguir viviendo, de que la vida (el pensamiento, el arte, la política, etc.) continúe $^{7}$. Se trata de la pugna que atraviesa todo intento de decir lo indecible, de poner en conceptos lo inconcebible, de modo que entre la necesidad de una representación, necesariamente dominadora, y la conciencia de la inaccesibilidad de lo que en su espanto continúa resultando amenazante ha de establecerse una relación de imposible reconciliación, que a pesar de ello no rompa la tensión no resuelta, abandonando cada uno de los extremos de la rela- 
ción a su suerte. Dentro de este horizonte se inscriben los intentos de afrontar la catástrofe "Auschwitz" por medio del arte.

\section{El arte y la negatividad radical}

Más que otras manifestaciones del espíritu humano se le atribuye precisamente al arte la capacidad de hacer justicia a lo inefable, a lo inexpresable. Por un lado, el arte se funda en la dimensión no conceptual propia de la experiencia estética y, por otro, está necesitado, para ser "comprendido", de la mediación conceptual, que si bien no es capaz de recuperar y explicitar lo inefable de modo acabado en el concepto, sí que puede arrancarlo de lo meramente vivencial, de modo que no sólo está referido lo estético al concepto, como también por cierto lo está el concepto a lo experimentado estéticamente, sino que la reciprocidad cooperativa de ambos polos es lo que confiere al arte una función cognitiva especialmente relevante para la cuestión que nos planteamos.

Sin embargo, la representación por medio del arte tiene su precio. Pues a pesar de todo lo perturbador, desgarrador y conmocionante que le es inherente (al menos al arte contemporáneo), éste incluye siempre una dimensión de despliegue del placer. La conmoción supuestamente perturbadora produce una satisfacción catártica, por muy ocultamente que ésta actúe, y en consecuencia una forma psíquica concreta de reconciliación. Se puede hablar incluso del placer del estremecimiento, que se produce allí donde es posible la cercanía a lo terrible sin peligro para el observador, y existe el voyeurismo que busca el placer estético en lo espeluznante y estremecedor desde la distancia de la seguridad. Toda representación de "Auschwitz" está amenaza por esta trampa.

Es más, la ambivalencia inherente a la relación entre el arte y la realidad en la producción, casi nunca es mantenida por los receptores, que más bien la resuelven suprimiéndola. Y este problema aumenta cuando el arte pierde su dimensión de autonomía (auto)crítica, aunque sea relativa, frente a la realidad dominante, para someterse a una determinación ajena, es decir, cuando se convierte en industria cultural. Es necesario resaltar esto especialmente en nuestro contexto, pues la industria cultural, más allá de la esfera del entretenimiento, no sólo se ha convertido en una especie de matriz interaccional de casi todos los ámbitos de la vida sino que se ha apoderado incluso del tema "Auschwitz"8.

Quizás sean estos peligros y la aguda conciencia sobre una cultura que, cuando no se convirtió en su cómplice, en todo caso no pudo resistir ni impedir la catástrofe, lo que llevó a Th. W. Adorno a formular en 1949 su famoso dictum sobre la complicidad de la lírica después de "Auschwitz" con la barbarie ${ }^{9}$. ¿Se trataba de un veredicto general sobre la poesía después de "Auschwitz", de una prohibición de la representación de "Auschwitz" en la poesía ${ }^{10}$ o de una provocación a la pretendida "resurrección cultural" 11 en la Alemania de la postguerra? A pesar de que no han sido pocos los que han querido leer en sus palabras una prohibición no sólo de la poesía, sino una impugnación de toda forma cultural ${ }^{12}$, en realidad lo que pretende formular Adorno es la situación aporética en que ha situado "Auschwitz" a toda la cultura: «Quién defienda la conservación de la cultura radicalmente culpable y mezquina se convierte en cómplice, mientras que quien rechaza la cultura promueve directamente la barbarie que reveló ser la cultura.» ${ }^{13}$

Pero, a pesar del nihilismo que moviliza la catástrofe de "Auschwitz" al cuestionar incluso si es posible seguir viviendo después ${ }^{14}$, Adorno no sólo considera un imperativo del pensamiento resistir frente a la 
locura que domina objetivamente en "Auschwitz", ${ }^{15}$ sino que ve en el arte una especie de historiografía inconsciente de la historia del sufrimiento y en las obras de los artistas auténticos el estremecimiento por el horror más extremo ${ }^{16}$. Por eso Adorno, en contradicción sólo aparente con sus manifestaciones anteriores, considera que el impulso negativamente expresado en su controvertido dictum es el mismo «que anima la poesía comprometida ${ }^{17}$.

La paradójica situación del arte después de "Auschwitz" viene dada por su responsabilidad en la memoria del sufrimiento, «dado que en casi ningún otro sitio encuentra el sufrimiento su propia voz, el consuelo que no lo traicione inmediatamente». Pero al mismo tiempo porque la creación artística, a pesar de toda irreconciliabilidad y dureza, convierte el sufrimiento real en imagen e inevitablemente hace de las víctimas obras de arte entregadas como pasto al mundo que las asesinó. El insuprimible potencial de placer que contiene el arte se convierte en un abismo hacia el que le empuja el imperativo moral de no permitir el olvido del sufrimiento real y la transfiguración del horror por el principio estético de estilización, termina arrancando un sentido a aquello que se resiste a toda afirmación del mismo. «Al convertirse incluso el genocidio en bien cultural dentro de la literatura comprometida, resulta más fácil seguir participando en la cultura que dio a luz el crimen.» ${ }^{18}$

Pero, pese a toda estilización estética y a los peligros que alberga, el sufrimiento ininterrumpido posee, según Adorno, un derecho de expresión ${ }^{19}$ y el arte es el «portavoz histórico de la naturaleza oprimida $»^{20}$. Así pues, el arte resulta imprescindible. Ahora bien, todo intento expresivo se ve impugnado por el sentimiento de culpa del que, destinado a la aniquilación, por azar escapó a ese destino. Como escribe Adorno, la posibilidad del testimonio proviene de la distancia que separa de las víctimas de las cámaras de gas. Lo que ha de ser testimoniado se sustrae permanentemente, al que intenta formularlo desde la distancia, del que ha escapado. "Auschwitz" obliga, pues, al arte a pensar y articular su propia imposibilidad. No puede tomar su derecho de existencia sin más por evidente. El arte sólo es posible al límite mismo del arte. Como es conocido, Adorno encuentra, entre otros, en Paul Celan esta articulación despojada de la ingenuidad culpable de un arte instalado en la evidencia de su derecho a existir y ciego frente a la catástrofe: «Esta lírica está penetrada por la vergüenza del arte a la vista del sufrimiento que se sustrae tanto a la experiencia como a la sublimación. Los poemas de Celan quieren decir el horror más extremo a través del silencio. $\mathrm{Su}$ mismo contenido de verdad es algo negativo.» ${ }^{21}$

Entre el mandato de recordar y expresar el sufrimiento y la prohibición de toda estetización del mismo, al arte sólo le queda un estrecho sendero que no puede recorrer sin asumir el precio de su propio fracaso, y quizás también buscarlo deliberadamente. El camino de la representación mimética de la catástrofe resulta intransitable tanto por la tendencia del arte contemporáneo a romper con la referencia realista al objeto como por las dificultades que el mismo objeto en este caso ofrece. Pero la pérdida de toda referencia a la realidad amenaza con hacer fracasar el cumplimento del imperativo expresivo de una realidad cuya singularidad precisamente es la que plantea la exigencia de la memoria. Por eso el arte comprometido con "Auschwitz" ha de renunciar a toda pretensión de representación o de explicación interpretativa y buscar el lugar de la re-presentación, de la presencialización de las experiencias de sufrimiento, lugar que él mismo no puede ser, pero al que debe conducir y apuntar. Ha de encontrar formas a través de las 
cuales ni se banalice ni se transfigure el sufrimiento, pero que tampoco transfigure la impotencia de las víctimas en creaciones dadoras de sentido. En definitiva, ha de destruir su propia soberanía y sentido y, al mismo tiempo, dar testimonio ${ }^{22}$. ¿Es esto posible?

Lyotard recurre en este contexto a la categoría kantiana de lo sublime (das Erhabene $)^{23}$, porque como en el caso del testimonio de la catástrofe lo que en ambos está en juego es la representación de lo irrepresentable. En "Auschwitz" la realidad desborda la capacidad de la imaginación. La maquinaria de violencia altamente eficiente tenía como meta la nada, la eliminación incluso del recuerdo del objeto de la aniquilación, hecho existir en gran medida por definición del procedimiento aniquilador mismo. Así, lo irrepresentable se presenta a la desbordada capacidad imaginativa como realidad de la nada consumada. Frente a esto, representar supone integrar en el orden de la memoria la diversidad de las impresiones, que quedan así inscritas en la conciencia. Dicha representación es condición de posibilidad del olvido, pues, frente a la opinión común, sólo lo registrado puede ser de nuevo borrado. La consecuencia de esto para la representación de "Auschwitz" es que todo «recuerdo representativo y representador conlleva y agranda el olvido del horror abismal que está a su base» ${ }^{24}$.

Frente a la estética de la representación nos encontramos en la Crítica del juicio con una estética del shock, con una anestética, que tiene que ver con la experiencia extática de la indeterminabilidad del mundo. Según Kant, la singularidad de lo sublime está en la confrontación perceptiva con datos o acontecimientos que, en su totalidad abrumadora, no pueden ser contemplados como un todo con sentido. El sentimiento de lo sublime, una especie de espasmo instantáneo que une placer y desagrado, atracción y rechazo, muestra «que un "exceso" "toca" al espíritu, excesivo como para poder hacer algo con ello. Por eso, lo sublime no tiene relación con la forma, es "informe" ${ }^{25}$. En la recepción de la estética de lo sublime por parte de Adorno quiere reconocer Lyotard la posibilidad de una estética "después de Auschwitz" que no se arroga la capacidad de representar lo sublime, que permanece intestimoniable. $\mathrm{El}$ arte «no dice lo indecible, sino más bien que no lo puede decir» ${ }^{26}$.

Pero el concepto kantiano de lo sublime es ambivalente en el sentido de que produce una subrepción, un juego de confusión entre objeto e idea, para poder representarse lo irrepresentable como irrepresentable. Y en esta subrepción está inscrita la lógica de la representación productiva, cuya tendencia, según Adorno, aboca en su realización acabada a lo más horrible. En lo sublime, en la contraposición entre imaginación y razón, se gesta el «sentimiento, de que nosotros tenemos una razón pura autónoma.» ${ }^{27}$ El sacrificio de la imaginación y la irrepresentabilidad de lo sublime -también del horror de las víctimas $^{28}$ - sirve a la hegemonización del sujeto, a la ampliación de su poder ${ }^{29}$.

Lo que queda escamoteado en el intento de Lyotard de recuperar la categoría kantiana de lo sublime en relación con la irrepresentabilidad de "Auschwitz" es la posición de distancia segura del espectador presupuesta por Kant, que permite, en el sacrificio de la imaginación, obtener o acoger un sentimiento de libertad y potencia de la razón mayor en todos los sentidos a la que se sacrifica. En el fondo, la cuestión que la categoría kantiana de lo sublime no ayuda a responder está referida a la legitimidad de una experiencia estética sustentada en el inimaginable -y a fortiori irrepresentable- sacrificio de las víctimas, bajo el presupuesto de la distancia del sujeto de esa experiencia respecto al horror, distancia cuyo olvido precede al olvido ine- 
vitable de las víctimas, inalcanzables por su imaginación y su capacidad representativa. Inevitablemente, en el instante sublime de la conmoción se ha de escenificar la irrepresentabilidad de lo irrepresentable, es decir, éste se ha de insertar en la estructura temporal de la experiencia del sujeto a salvo del horror, en definitiva, se ha de someter la irrepresentabilidad a la lógica de la representación.

Por esa razón habría que ir más allá y volver el derrumbamiento de la imaginación que se significa en lo sublime contra la construcción misma de lo sublime. La conciencia de la irreducible coexistencia del derrumbamiento de la representación y la representación del derrumbamiento en la experiencia de lo sublime implica la otra experiencia de que incluso el cumplimiento más logrado de la coexistencia de ambos polos se alimenta de la contraposición entre ambos. Sublime sólo es aquella percepción de las posibilidades perceptivas que ni se inclina ante la genialidad ni ante el «dictado de la ausencia de conflicto» ${ }^{30}$. La praxis de lo sublime ha de apropiase más bien aquel «gesto de salirse» que leyó Adorno en los textos de Kant sobre lo sublime, para luego volverlo contra todo intento de privilegiar el arte o instrumentalizarlo desde la filosofía de la historia ${ }^{31}$. La opción por la categoría de lo sublime es también la opción por una cultura del conflicto que lo mantenga libre frente a la existente y amenazante cultura de la integración. Dicha cultura del conflicto no puede ser meramente estética, no puede agotarse en la producción artística, sino que tiene que ser al mismo tiempo moral y política.

Pero veamos ahora hasta qué punto estas reflexiones generales reflejan o no las exigencias que se siguen del testimonio de los supervivientes de la catástrofe, que tomamos aquí como criterio orientador de la reflexión estética sobre la (ir)representabilidad de "Auschwitz".

\section{El testimonio necesario e (im)posible}

Como afirma P. Levi, parece «natural y obvio que la fuente esencial para la reconstrucción de la verdad en los campos de concentración esté constituida por las memorias de los supervivientes.» ${ }^{32} \mathrm{Y}$ sin embargo nadie como él ha problematizado esta misma afirmación. De los "auténticos" testigos de la catástrofe, de aquellos que han visto "la Gorgona" ${ }^{3}$, que han tocado fondo, es decir, de la inmensa mayoría, sólo nos queda el silencio que ha dejado su total aniquilación, una aniquilación que, conforme al propósito de sus verdugos, alcanza incluso hasta los últimos vestigios de su existencia transformada en humo y cenizas anónimas. Quizás por ello, el testimonio de los supervivientes es un testimonio "quebrado" 34 , un testimonio sobre la imposibilidad del testimonio, como refleja la palabra indescifrable -«mass-klo, matisklo»- del niño Hurbinek, único resto de una vida segada en su origen, que recoge P. Levi en La tregua ${ }^{35}$. Esta palabra representa una doble imposibilidad de testimoniar: la del hundido que se ha llevado consigo el enigma de su palabra (y de su vida/muerte) y la del testigo, cuya lengua ha de «ceder su lugar a una no lengua, mostrar la imposibilidad de testimoniar» ${ }^{36}$. Encadenados a la catástrofe, que los supervivientes experimentan en una contemporaneidad que impide cancelar el pasado, se les impone de modo ineludible la prohibición de callar, de resistir al olvido y al silenciamiento pretendido por los verdugos, pero todo ello bajo una conciencia extremadamente lúcida de la imposibilidad de hablar ${ }^{37}$.

Una de las claves para entender esa imposibilidad se encuentra en la incomprensibilidad de los hechos vividos y presenciados $^{38}$. Resulta imposible comprender el "universo concentracionario" 39 para los que fueron sus víctimas, para los que 
quedaron atrapados en él ${ }^{40}$. Como dice Adorno, «en los campos de concentración del fascismo se eliminó la línea de demarcación entre la vida y la muerte. Estos campos crearon un estado intermedio, esqueletos vivos y seres putrefactos, víctimas a las que les falló el suicidio y la risa de Satanás sobre la esperanza de vencer a la muerte. ${ }^{41}$ Esto aparece repetidamente en los testimonios de los supervivientes. Ninguna situación en los campos de concentración era calculable, no existía un sistema espacial y temporal de reglas, al que sometiéndose al menos se pudieran elevar las expectativas de una posible supervivencia. La muerte era omnipresente, se había transmutado en la supuesta vida de los deportados y se había vuelto indistinguible de ella. "Vivir en Auschwitz" significaba no seguir en vida. Esta es la razón que convierte a los 'musulmanes' -palabra con la que se denominaba a los que caían en estado de máxima degradación y cuyo significado se corresponde con "cadáveres ambulantes" $"$ - en el "testigo integral" ${ }^{43} \mathrm{del}$ universo concentracionario.

De ahí la machacona repetición de los supervivientes a quienes los leen o los escuchan: por mucho que quieran nunca llegarán a entender, pues el mundo llamado "normal" y el mundo de los campos de exterminio resultan inconmensurables ${ }^{44}$. Nuestro mundo, definido por usos lingüísticos concretos, se diferencia de modo esencial de aquel en que existieron y vivieron las víctimas. De modo que el conflicto entre la necesidad de ser escuchado y la imposibilidad de serlo de hecho acompaña traumáticamente el retorno de casi todos los supervivientes, y ello incluso en el caso de que existieran personas dispuestas a escuchar ${ }^{45}$, lo que para muchos fue más bien una excepción ${ }^{46}$. Viven además un profundo temor a que los receptores del testimonio ignoren el foso que separa los dos mundos y realicen una "comprensión" precipitada, que estetice o funcionalice dicho testimonio ${ }^{47}$. Es un temor a hacerse cómplices de una traición a los muertos y a su memoria, bajo la apariencia de una comunicabilidad que ignora el abismo que la atraviesa y frustra ${ }^{48}$.

No puede extrañar que el silencio se convierta en el núcleo del testimonio, como refleja E. Wiesel: «Lo que yo intento hacer es introducir tanto silencio como sea posible. Desearía que mi obra no sea juzgada un día por las palabras que he escrito, sino por su peso en silencio. Si pudiera comunicar el silencio, es decir, la incomunicabilidad, entonces habría justificado en una pequeña parte mi propia obra ${ }^{49}$. Evidentemente no se trata de una complicidad con el silencio culpable de los verdugos y sus colaboradores, sino de hacer presente la "interrupción" del discurso en el discurrir de la palabras, de modo que las quiebras abran el espacio comunicativo a la ausencia de sentido de tanto dolor y sufrimiento como se acumulan en "Auschwitz". El testimonio crea la paradoja de un silencio audible, aunque por desgracia nos haya sido impuesto el legado de otro silencio inaudible que resuena en el interior de las cámaras de gas y cuyo texto nunca podremos conocer. Ese silencio sigue siendo inaccesible y permanecerá para siempre inaudible.

Otras de las claves que permiten acercarse a la comprensión de la imposibilidad de testimonio necesario proviene del mismo carácter traumático de la experiencia de los supervivientes. La comunicación de dicha experiencia supone en todos los casos una reproducción del trauma que amenaza con arrastrar a los testigos de nuevo al abismo. El suicidio de Paul Celan, Jean Améry, Primo Levi y Bruno Bettelheim, así como el testimonio referido más arriba de Jorge Semprún, atestiguan claramente con cuanta frecuencia el dar testimonio se produce como bajo coacción y como responsabilidad forzosa que no libera de ninguna manera. Hablar no pro- 
duce ningún alivio, sino más bien una retraumatización. Es más, podría decirse que, debido a su violencia, el acontecimiento traumático no puede ser completamente experimentado, no puede estar completamente presente a la conciencia, en el momento de suceder, por ello se sustrae a los parámetros de la temporalidad "normal" y escapa a la sucesión de experiencias unidas por una cierta analogía, lo que genera las dificultades de comprensión, narración y control ${ }^{50}$. Su forma específica de ser experimentado es reaparecer continuamente, es ser revivido. Dado que no puede ser reelaborado e integrado desde el punto de vista experiencial, permanece sin clausurar, sin final ${ }^{51}$. Así pues, si por un lado, la transformación del trauma en narración posibilita su conocimiento individual y colectivo, no puede olvidarse que por otro le hace perder su tan esencial incomprensibilidad y, con ello, su ataque a la comprensión satisfecha de sí $^{52}$.

A diferencia del recuerdo en sentido habitual, la memoria de "Auschwitz" no puede ser integrada en la economía interior de un tiempo que sigue el orden secuencial. Más bien se presenta como un poder perturbador y resistente frente a todos los intentos de confirmar con él convicciones, de llegar a resultados o de obtener certezas. El pasado de los testimonios es un pasado siempre presente, un pasado que dura. Por ello, frente a la apariencia de diacronía que produce la narración, en el trauma tenemos que ver con un tiempo no secuencial, en el que el presente es pasado y el pasado está y es presente ${ }^{53}$. De ahí se derivan las dificultades del discurso frente a un acontecimiento que, a causa de su persistencia, se sustrae a su integración en la sucesión temporal de un antes, un durante y un después. Cuando asistimos a declaraciones de testigos, nos encontramos en el presente de un pasado que no fue ni puede ser borrado, de un momento que no nos es tanto representado cuanto más bien re-presentado, que se nos presenta de nuevo. En sentido estricto no se trata de un recuerdo, porque tampoco ha habido olvido, «puesto que [...] sólo puede ser olvidado aquello que ha sido registrado o representado, lo que ha sido descrito (en palabra o imagen o forma).» 54

La ilusión que crea la narración nos empuja a creer que la situación de las víctimas ha quedado integrada dentro de una sucesión cronológica dominada por modelos de experiencia compartida en la que el sufrimiento y la muerte son comúnmente transcendidos hacia un resultado que los supera, pero "Auschwitz" se resiste a esta integración ${ }^{55}$. Esa negatividad no tiene ningún sentido, no hace avanzar la historia, no se resuelve en un resultado ${ }^{56}$. "Auschwitz" es una herida no cicatrizable. En la confrontación con los testimonios de los supervivientes, no es nuestro esquema temporal el que puede ofrecer el marco integrador. Más bien encontramos en dichos testimonios interrupciones que ponen de manifiesto las limitaciones del tiempo secuencial que nos ofrece seguridad y asilo. La lógica de la permanencia del trauma impide el alivio que concede el tiempo cronológico, que es el que hace posible el olvido. Por eso toda narración conclusiva que niega el presente del horror se coloca del lado de los verdugos y no del lado del sufrimiento persistente a causa del pasado.

Por otro lado, para que la experiencia extremadamente traumática de "Auschwitz" pueda salir a la luz, los testigos necesitan de una "audiencia", lo que L. Langer llama «testigos de la memoria» ${ }^{57}$, es decir, de personas dispuestas a asumir responsabilidad respecto a la realidad testimoniada que no ha sido experimentada por ellos mismos. Cabría incluso decir que sin un interlocutor, sin una persona que escucha, la manifestación del testigo no puede devenir testimonio. El recuerdo es evocado 
para dirigirse a alguien, para apelar a un oyente o para encontrar oído en una comunidad. Esto convierte a quien es interpelado en participante en la lucha de la víctima con sus recuerdos y con los residuos del pasado traumático ${ }^{58}$. Pero si, como hemos visto, la cuestión del testimonio vista desde el punto de vista del testigo está plagada de aporías, ¿puede existir algo así como una corresponsabilidad de los no afectados respecto al testimonio del pasado o incluso un testimonio vicario de los que no han vivido la experiencia ni siquiera de cerca? ¿No puede entonces producirse una confusión entre la auténtica experiencia del sufrimiento y un sufrimiento meramente representado? ¿Es la identificación con las víctimas la actitud correcta o más bien conduce ésta a una satisfacción del interlocutor por medio de la proyección de sí mismo? ¿De qué manera influye en la percepción del sufrimiento ajeno y en la respuesta moral al mismo la masiva e ininterrumpida presentación del sufrimiento "lejano" servida por los medios de comunicación, a veces live, pero desconectada casi siempre de toda vinculación responsabilizadora? ¿Puede conducir la confrontación con el sufrimiento del pasado y con los sufrimientos de otros hoy a una acción responsable, en vez de acabar en la identificación imposible con las víctimas, la represión, la conmiseración políticamente paralizante, la fijación melancólica o el estupor mudo ante lo extraño de la experiencia traumática?

Toda identificación corre peligro de convertirse en hiperidentificación y de llevar a una personificación y, en definitiva, a una apropiación de identidades. Pero, por otro lado, la posición de espectador es extremadamente incómoda, pues la reproducción mental de los acontecimientos dolorosos no sólo nos expone a una forma aunque sea amortiguada de trau$\mathrm{ma}^{59}$, sino a la inquietud de no sentir suficiente empatía. ¿Puede establecer la dis- tancia estética un equilibrio entre una escasa y una excesiva identificación? Lo errático de la senda de la identificación salta a la vista si tenemos en cuenta que un elemento clave de la política de exterminio fue arrebatar a las víctimas toda forma de identidad, en establecer un abismo insalvable entre el ser persona y ser judío. «La identidad de las víctimas se convirtió en no- identidad $»^{60}$. Es necesario resistir a la tentación de buscar en los testimonios de los supervivientes un mensaje heroico o salvador, pues esta actitud destruye la posibilidad de un verdadero escuchar y revela una autodefensa frente a la conciencia de la irreparabilidad de "Auschwitz"61. La persona que escucha tiene que escuchar y percibir el silencio en el que tantas veces se refugian los supervivientes y que habla sin palabras desde el callar y desde el hablar, desde más allá del lenguaje y desde el lenguaje.

A todas las cuestiones sobre los límites estéticos y morales de la representación artística del holocausto, cuestiones que han dominado la discusión en torno a la catástrofe de "Auschwitz" hay que unir hoy la cuestión no menos relevante referida a la posibilidad de transmitir la significación del acontecimiento a generaciones nacidas medio siglo o más después del acontecimiento. Y no se trata sólo de transmitir dicha significación, sino también las razones que generaron y generan los mencionados problemas de representación y recuerdo. Muchos desconocen esas dificultades y no siempre comprenden su vigencia y actualidad. Prefieren formas más efectivas y adaptadas a la discusión actual de ofrecer el acontecimiento en películas o en el debate televisivo del programa nocturno. Muy raramente se llegan a tocar los límites verdaderos de la representación.

Pero si Detlev Claussen tiene razón, no es el debilitamiento de la memoria lo que ha desplazado a "Auschwitz" del horizonte 
cultural occidental, sino su transformación en un bien cultural asimilado por la industria cultural bajo lo que él llama «el artefacto 'Holocausto'» ${ }^{62}$. En dicho artefacto las leyes de la comunicabilidad empujan hacia el realismo convencional que conecta con las formas habituales de pensar y ver del gran público. El lugar del silencio, que no era sólo signo del olvido, sino que también podía ser ocupado por el recuerdo, es suplantado por la ilusión de la comunicabilidad universal. Emocionalidad, identificación con los héroes ejemplares, el juego entre aumento de la tensión y descarga aliviadora de la misma, la lógica del happy end, la superación de la impotencia y la desesperación, etc. dominan la escena para hacer conmensurable el horror más extremo. «La producción de la industria cultural demuestra su ilimitada plenitud de poder precisamente en que el arsenal de comunicabilidad parece omniabarcante e inagotable. No puede dejar nada irrepresentable, es decir, incomunicable. La dominabilidad del mundo debe probarse precisamente en que todo es representable. ${ }^{63}$ Esto se corresponde con el supuesto horizonte de comprensión de los receptores que, en su transitar habitual por mundos virtuales, prefieren el kick mediático a verse arrollados existencialmente por lo que escapa a la comunicabilidad. Porque en el mundo mediático, como señala Baudrillard, «no hay tiempo para el silencio. El silencio está expulsado de las pantallas, expulsado de la comunicación.» ${ }^{64}$

\section{¿Imágenes del horror?}

Tomamos ahora las reflexiones precedentes como guía para enfrentarnos a un ámbito de expresión estética especialmente relevante en la industria de la cultura, que hoy es tanto como decir en la cultura en general: el cine ${ }^{65}$. Ningún medio artístico parece más capacitado que el cine para realizar un representación de la facticidad histórica fiel a la realidad. Pero en realidad todos los trabajos fílmicos, desde los documentales a las series televisivas, tienen una dimensión de construcción y escenificación $^{66}$. Por eso quizás la diferencia no se encuentre en la ausencia o no de esa dimensión, sino en que unas obras intentan sugerir una autenticidad representativa que sugiere la ausencia de construcción y otras la tematizan expresamente. Sobre esto podríamos distinguir también aquellas obras cinematográficas en las que el recuerdo de los supervivientes constituye la textura misma del film, cuyo representante más señalado es la película de C. Lanzmann Shoah, y aquellas otras que buscan más bien realizar por medio del film una reconstrucción del pasado, como la serie televisiva Holocausto o la película de Spielberg La lista de Schindler.

Estos dos últimos ejemplos adoptan los elementos esenciales de la forma de narrar de Hollywood, que según Ilan Avisar, son la inducción de expectativas y su gratificación en una estructura coherente, la estimulación por medio del envolvimiento emocional en el destino de los personajes y la introducción de posicionamientos ideológicos en la acción de las figuras dramáticas a través de la manipulación de la reacción empatizadora del espectador ${ }^{67}$. Esta estructura hace de marco para las posibles heridas anímicas, que en cualquier caso han de estar restañadas cuando se encienda la luz de la sala de proyección. Toda violación de la seguridad del espectador debe quedar pacificada y el trauma reprimido, olvidado, privatizado o desplazado al pasado, es decir, sometido a las estrategias de descarga y alivio.

Spielberg sigue de manera magistral estas reglas narrativas en La lista de Schindler. Primero construye una retórica de la autenticidad a través del uso del blanco y negro y de la incorporación de los supervivientes en la escena final. La pelí- 
cula obtiene así un respaldo incomparable a la supuesta fidelidad a los hechos, que relativiza la quiebra entre ficción y acontecimiento. Música, sonido, iluminación y fotografía está al servicio de envolver al espectador siguiendo la lógica de la identificación. Con los mecanismos del cine convencional son generadas las necesidades de identificación a las que se somete después la lógica de la superviviencia y de la muerte. La mayoría de personajes sobre los que descansa la carga de satisfacer dichas necesidades están destinados a la supervivencia. Frente a la realidad apabullante testimoniada por los supervivientes de que escapar a la maquina aniquiladora sólo podía responder al azar, la película de Spielberg sugiere que la buena voluntad individual y algo de coraje en el ámbito de influencia individual bastan para vencer al mal. Esto responde al optimismo salvífico que sirve de telón de fondo a la construcción narrativa. La excepción en la realidad -la supervivencia- focaliza toda la construcción ficcional hacia la salvación de los judíos de Schindler, que una vez superado el infierno pueden comenzar de nuevo el curso normal de la vida. "Volver a la normalidad" resuelve en salvación la tensión generada deliberadamente a través de la identificación.

Quizás la secuencia más atrevida de toda la película, aquella que más tabúes rompe en torno a la irrepresentabilidad de "Auschwitz", sea la que escenifica lo ocurrido en las cámaras de gas ${ }^{68}$. Spielberg advierte previamente al espectador del destino que espera las víctimas y después va acompañado con la cámara su camino hacia la muerte. Con ayuda de los movimientos de la cámara entrecruza las perspectivas irreconciliables de los verdugos, los observadores y las víctimas, pero no ofrece la posibilidad de tematizarlas, de pensar su irreconciliabilidad. Incluso el voyeurismo es explícitamente apuntado en la mirada por la ventanilla de la puerta de la cámara. Pero el problema es sobre- seído por el movimiento mismo de la cámara. En las escenas del interior, Spielberg no duda en sacar todos los registros de los mecanismos de identificación a lo Hollywood, hasta la sugerente belleza del desnudo femenino. La tensión asciende hasta el paroxismo y crece extraordinariamente la necesidad emocional producida con verdadera maestría. Pero la angustia y el miedo ante la muerte inminente dan un vuelco en alegría: de las duchas hacia las que se elevan las miradas en espera de una especie de acto de gracia venido de lo alto brota agua, simplemente agua. La salvación ha sido posible. La carrera contra el reloj del benefactor Schindler, que es recogida en la acción paralela, ha dado su fruto. El bien sigue activo en el mundo.

No puede haber mayor contraste entre esta escenificación y la retórica de la autenticidad que preside toda la película. La construcción narrativa de La lista de Schindler pone en primer plano la salvación y no la aniquilación. Sugiere que la historia posee un sentido, más que mostrar el fracaso de todas las estrategias de donación de sentido después de Auschwitz. Privilegia el destino individual del héroe por encima de los demás implicados, concediendo el mayor espacio a los supervivientes, a pesar de su reducidísimo número frente a los aniquilados. Y termina reduciendo "Auschwitz" a una prehistoria de la reintegración en la normalidad. En $\mathrm{La}$ lista de Schindler triunfan las exigencias de la industria cultural sobre las exigencias derivadas del acontecimiento objeto de la película.

El film Shoah de Lanzmann representa el mayor contrapunto a la obra de Spielberg. En su crítica de esta última el propio Lanzmann formula la convicción más profunda que preside su trabajo, «que toda representación está prohibida ${ }^{69}$. Sería crear imágenes idealistas al servicio de la identificación consoladora. Este rechazo de la representación mimética en la ficción 
toma como criterio la experiencia de los supervivientes, sus dificultades para narrar lo ocurrido, para encontrar palabras. Lanzmann opta, pues, por mantener la tensión testimonial que recoge la imposibilidad de testimoniar desde el exterior (los salvados) y desde el interior (los hundidos) ${ }^{70}$.

Frente a las funciones típicas del material fílmico o fotográfico de carácter documental, establecer la prueba óptica de la evidencia y una impresión de autenticidad, es decir de la realidad de lo visto y de su pertenencia al pasado en cuestión, la renuncia al material documental supone la negación de estas dos funciones. No existe posibilidad de establecer por medio de un testimonio fílmico la conexión entre el gigantesco aparato de aniquilación exterior y el asesinato mismo en el interior del campo de exterminio. Dicha aniquilación tampoco puede ser convertida en un pasado concluso y acabado ${ }^{71}$. Por eso la autenticidad de Shoah no se basa en la correspondencia con algo que está fuera o más allá de la situación que produce el mismo film. El sello de lo auténtico no proviene de una fidelidad al pasado o de la escenificación adecuada de lo que ocurrió, sino de la actualización de la conmoción que sigue actuando en el testigo.

Por esa razón Shoah no utiliza ningún material de imágenes ya existente, ni usa fondo musical que refuerce la provocación de sentimientos en el espectador ${ }^{72}$. También renuncia al comentario interpretativo de lo que se muestra. Todas las entrevistas y las imágenes proceden del presente. Lanzmann registra los recuerdos traumá- ticos y horribles de las víctimas y también la mendacidad y la falsedad de los verdugos, sus pobres defensas y su violencia. Pero se cuida muy bien de diferenciarlas en la escenificación, en el uso de la cámara y en el montaje. En los testimonios no trata de acumular recuerdo del pasado, sino de escenificar el retorno de lo vivido ${ }^{73}$. Intenta captar lo somático del shock traumático que se sustrae precisamente a la manifestación comunicativa del recuerdo en cuanto proceso consciente. Los escenarios históricos, muchos de los cuales han perdido todo rastro del genocidio o los espacios escénicos sustitutorios pretenden ser detonantes, punto de enganche del detalle traumático. Por eso resultan tan significativas las manifestaciones involuntarias del cuerpo que testimonian el efecto persistente de lo vivido ${ }^{74}$. El cuerpo del superviviente hospeda mutilaciones que revelan que la traumatización no ha sido superada. Lanzmann no muestra a salvados, sino a mutilados.

Esto es lo que convierte a Shoah en una película no sólo de testimonios, sino sobre el testimonio, sobre lo que significa convertirse y ser testigo de la catástrofe. La relación entre arte y testimonio es ella misma objeto de la propia obra de arte, con el fin de hacernos testigos de la crisis histórica del testimonio. La obra de arte no transfigura las heridas y las quiebras, ni las integra en una totalidad dadora de sentido. Lo que se hace visible es la acción misma de recordar, sus dificultades, la búsqueda de la palabra, pero también el silencio.

\section{NOTAS}

\footnotetext{
${ }^{1}$ El nombre Auschwitz, utilizado como sinécdoque para referirse al genocidio judío, es preferible a otros términos como Holocausto (cargado de significación teológica), Shoah (caracterización como catástrofe incomparable 'dentro' la historia del pueblo judío) o
}

Jurban (continuidad del genocidio con otras catástrofes de dicha historia). Sobre el significado de estos términos, cfr. J. E. Young: Beschreiben des Holocaust. Darstellung und Folgen der Interpretation. Fráncfort 1997 (orig. ing., 1988), p. 139ss. En este texto utili- 
zaremos el nombre "Auschwitz" entre comillas para referirnos a esta catástrofe que afecta a la toda historia y que culminó en el universo de los campos de concentración y de exterminio. Quien dice "Auschwitz" quiere decir cámaras de gas. En ellas sucedió lo que ese nombre nos encarga recordar y obliga a pensar.

${ }^{2}$ Esto no afecta sólo a la representación post factum, sino como ha puesto de relieve James E. Young también a la experiencia en el momento de tener lugar. Cfr. James E. Young: Beschreiben des Holocaust. Fráncfort 1997 (orig. ing., 1988), p. 20.

${ }^{3}$ M. Postone: «Nationalsozialismus und Antisemitismus. Ein theoretischer Versuch», en: D. Diner (ed.): Zivilisationsbruch. Denken nach Auschwitz. Fráncfort 1988, p. 243. Si quisiéramos determinar la singularidad de Auschwitz, habría que buscarla probablemente en la decisión sin precedentes y respaldada con toda la autoridad de un estado de asesinar a todo un grupo humano, incluidos ancianos, mujeres y niños, a ser posible sin dejar resto, y de liberar todos los medios estatales posibles para la ejecución de dicha decisión (cfr. E. Jäckel: «Die elende Praxis der Untersteller. Das Einmalige der nationalsozialistischen Verbrechen lässt sich nicht leugnen», en: "Historikerstreit». Die Dokumentation der Kontroverse um die Einzigartigkeit der nationalsozialistischen Judenvernichtung. Múnich 1987, p. 118). Sobre los posibles excesos de la tesis de la singularidad de "Auschwitz", cfr. T. Todorov: Los abusos de la memoria. Barcelona 2000 (orig. fr., 1995), p. 34ss.

${ }^{4}$ Maurice Blanchot lo llega a denominar "acontecimiento absoluto de la historia" (L'écriture du désastre. Paris 1980, p. 80).

${ }^{5}$ Dan Diner ha acuñado este término en referencia explícita a Horkheimer y Adorno. El genocidio judío «pone de manifiesto una quiebra civilizatoria de carácter universal. Dicha quiebra tiene su fundamento en el hecho de que una aniquilación sin motivo alguno de seres humanos haya sido posible y real» (D. Diner: «Aporie der Vernunft», en: D. Diener: Zivilisationsbruch, op. cit., p. 31). La referencia a Horkheimer y Adorno en p. 33.

${ }^{6}$ Cfr. N. Berg: "“Auschwitz" und die Geschichtswissenschaft - Überlegungen zu Kontroversen der letzten Jahre», en: N. Berg -J. Jochimsen- B. Stiegler: Shoah - Formen der Erinnerung: Geschichte, Philosophie, Literatur, Kunst. Munich 1996, p. 31-52.

${ }^{7}$ J. Semprún nos revela la razón del abandono de su intentos inmediatos de elaborar literariamente las experiencias del campo de concentración: «Hubiera sido imposible sobrevivir a la escritura. El único final previsible de aquella aventura de querer dar testimonio hubiera sido mi propia muerte. [...] Tuve que elegir entre la escritura o la vida, y me decidí por la vida» (Discurso con motivo de la concesión del Premio de la Paz de los libreros alemanes 1994, Börsenverein des Deutschen Buchhandelns e.V.: Friedenspreis des Deutschen Buchhandelns 1994: Jorge Semprún. Fráncfort 1994, p. 36). Esta experiencia refleja de modo cabal la cuestión planteada por Adorno en la Dialéctica Negativa, de si es posible seguir viviendo después de Auschwitz, pues para seguir viviendo se «necesita la frialdad, principio fundamental de la subjetividad burguesa, sin la que no hubiera sido posible Auschwitz: culpa drástica del que escapó» (Th.W. Adorno: Negative Dialektik, en: Gesammelte Schriften [cit. GS] 6, Fráncfort 1973, p. $355 \mathrm{~s}$.).

${ }^{8}$ Imre Kertész, sobreviviente de Auschwitz, denuncia con razón el progresivo despliegue de una especie de «conformismo en torno al holocausto, un sentimentalismo del holocausto, un canon del holocausto, un sistema de tabúes del holocausto y un mundo lingüístico ceremonial correspondiente con todo ello; productos sobre el holocausto para consumidores del holocausto». (Imre Kertész: «Wem gehört Auschwitz?», en: Die Zeit, 19.11.1998).

${ }^{9}$ Cfr. Th. W. Adorno: «Kulturkritik und Gesellschaft», en: GS 10, Fráncfort 1977, 30. La controversia en torno a esta afirmación de Adorno ha generado cientos de páginas. Cfr. entre otros Lyrik nach Auschwitz? Adorno und die Dichter. Ed. por P. Kiedaisch. Stuttgart 1995; D. Claussen: «Nach Auschwitz kein Gedicht? Ist Adornos Diktum übertrieben, überholt und widerlegt?», en: H. Welzer (ed.): Nationalsozialismus und Moderne. Tubinga 1993, p. 240-247; D. Lamping: «Gedichte nach Auschwitz, über Auschwitz», en: G. R. Kaiser (ed.): Poesie der Apokalypse. Würzburg, 1991, 237-257; O. Lorenz: «Gedichte nach Auschwitz oder: Die Perspektive der Opfer», en: Bestandaufnahme der Gegenwartsliteratur. Sonderband. Ed. por H. L. Arnold. Munich 1988, 35-54.

${ }^{10}$ E. Wiesel rechaza la existencia de una Literatura sobre "Auschwitz". "Una novela sobre Auschwitz o no es una novela o no es sobre Auschwitz» (E. Wiesel: «Art and Cultur after the Holocaust», en: E. Fleischer (ed.): Auschwitz: Beginning of a New Era? Reflections on the Holocaust. Nueva York 1974, p. 405. Sarah Kofman va más allá y rechaza de modo radical no sólo la literatura sobre "Auschwitz", sino también ciertos intentos de narrar historias sobre acontecimientos como si la catástrofe que ha quebrado toda continuidad histórica no hubiese destruido con ella el idílico informe ficcional basado en la claridad, la continuidad, la causalidad, la seducción y el sentido. Este tipo de literatura narrativa pertenece al tiempo pre-"Auschwitz" aunque haya sido escrita y publicada después de 1945 (cfr. S. Kofman: Paroles suffoquées. Paris 1987, 43). Después de "Auschwitz" toda expresión artística y no sólo el arte sobre la catástrofe está afectada y transformada por ella.

${ }^{11}$ Cfr. Id.: «Die auferstandene Kultur», en: GS 20, Fráncfort 1986, 453-464. El horizonte del mencionado dictum de Adorno viene dado por la necesidad posbélica de convertir la reintegración de Alemania en la tradición cultural occidental en instrumento para silenciar la catástrofe. La provocación de Adorno se dirigen contra la creencia de que con la tradición reclamada se puede eliminar la anticultura y la barbarie 
acontecida (Cfr. S. Kramer: Auschwitz im Widerstreit. Zur Darstellung der Shoah in Film, Philosophie und Literatur. Wiesbaden 1999, p. 70ss.).

${ }^{12}$ En la Dialéctica negativa encontramos formulada con total claridad esta radical impugnación: «Toda cultura después de Auschwitz, incluida la urgente crítica a la misma, es basura» (op. cit., p. 360).

13 Th. W: Adorno: Negative Dialektik, en: GS 6, Fráncfort 1973, p. 360.

${ }_{14}$ Op. cit., p. 355.

${ }^{15}$ Cfr. Id.: Minima Moralia, en: GS 4, Fráncfort 1980, p. 115.

${ }^{16}$ Cfr. Id.: «Jene zwanziger Jahre», en: GS 10, Fráncfort 1997, p 506.

${ }^{17}$ Id:: «Engagement», en: GS 11, Fráncfort 1974, p. 422.

${ }^{18}$ Op. cit., p. 424.

${ }^{19}$ Cfr. Id:: Negative Dialektik, op. cit., p. 355.

${ }^{20}$ Id.: «Paralipomena zur ästhetischen Theorie», en. GS 7, Fráncfort 1973, p. 365.

${ }^{21}$ Op. cit., p. 477. Sobre silencio y poesía después de Auschwitz cfr. H. Korte: "Es ist in aller Trauer der tiefste Hang zur Sprachlosigkeit". Der Holocaust in der Lyrik nach 1945», en: Text und Kritk, no 144: Literatur und Holocaust (1999), p. 25-47; V. Lenzen: " "Reden ist schwer, schweigen unmöglich" (Elie Wiesel). Sprache und Schweigen im Schatten der Shoah", en: R. Boschki -D. Mensink (eds.): Kultur allein ist nicht genug. Das Werk von Elie Wiesel - Herausforderung für Religion und Gesellschaft. Münster 1998, p. 58-71.

${ }^{22}$ Cfr. J. Klein: «Schreiben nach Auschwitz. Die französische Debatte», en: Germanisch-Romanische Monatsschrift. Nueva Serie 44 (1994), p. 205-213.

23 I. Kant: Kritik der Urteilskraft, en: Werke in zehn Bände, T. 8, (5ª ed.) Darmstadt 1983, 328ss. (A, 73ss; $\mathrm{B}, 74 \mathrm{ss}$.). «El asombro, que raya en el sobresalto, el escalofrío y el espanto sagrado que sobrecoge al espectador al contemplar los macizos montañosos que escalan el cielo, las gargantas profundas y las aguas que braman en ellas, los yermos profundamente umbríos que invitan a pensamientos melancólicos, etc. no es, en la seguridad en la que se sabe, verdadero temor, sino sólo un intento de abandonarnos a ello con nuestra imaginación para experimentar el poder de esa misma facultad, enlazar el movimiento de ánimo provocado a través de ello con la tranquilidad y, de esa manera, ser superior a la naturaleza en nosotros, por consiguiente también a la naturaleza fuera de nosotros, en tanto ella puede tener influencia sobre el sentimiento de nuestro bienestar.» (Op. cit., p. 359 (A, 116; B, 117).

${ }^{24}$ F. Lyotard: Heidegger und "die Juden". Ed. por P. Engelmann. Viena 1988 (orig. fr. 1988), p. 42; cfr. W. Bialas: «Die Shoah in der Geschichtsphilosophie der Postmoderne», en: Shoah-Formen der Erinnerung, op. cit., p. 107-121

${ }_{25}$ Op. cit., p. 45.

${ }^{26}$ Op. cit., p. 59.
${ }^{27}$ I. Kant: Kritik der Urteilskraft, op. cit., p. 346 (A, 98; B, 99).

${ }^{28}$ Es el mismo Kant el que se refiere a esta realidad: «Incluso la guerra, cuando se lleva a cabo con orden y respeto sagrado de los derechos burgueses, tiene algo de sublime en sí». (Op. cit., p. 351 (A, 105; B, 107).

${ }^{29}$ Cfr. Op. cit., p. 359 (A, 115; B, 117).

30 Th. W. Adorno: «Das Schema der Massenkultur», en GS 3, Fráncfort 1981, p. 309.

${ }^{31}$ Th.W. Adorno: Ästhetische Theorie, en: GS 7, Fráncfort 1973, p. 100ss.

32 P. Levi: Los hundidos y los salvados. Barcelona 2000 (orig. it., 1986), p. 15. Sobre el concepto de supervivientes, cfr. R. Hilberg: Täter - Opfer - Zuschauer. Die Vernichtung der Juden 1933-1945. Fráncfort 1992, p. 208. Ver también B. Bettelheim: Sobrevivir. El Holocausto una generación después. Barcelona ${ }^{2} 1983$ (orig. ing. 1979).

${ }^{33}$ Cfr. P. Levi: Op. cit., p. 73.

${ }^{34}$ Cfr. J. Améry: Jenseits von Schuld und Sühne. Bewältigungsversuche eines Überwältigten. Munich 1988 , p. 13. Ver también M. Blanchot: Après coup, précédé par Le ressassement éternel. Paris 1983, p. 98.

${ }^{35}$ P. Levi: La tregua. Barcelona ${ }^{3} 1997$ (orig, it. 1963), p. 21ss.

${ }^{36}$ Cfr. G. Agamben: Lo que queda de Auschwitz. El archivo y el testigo. Homo sacer III. Valencia 2000 (orig. it., 1999), p. 39.

${ }^{37}$ Cfr. J. Semprun -Elie Wiesel: Schweigen ist unmöglich. Fráncfort del Meno 1997 (org. fr. 1995), p. 18.

${ }_{38}$ Se trata de un testimonio repetido. Cfr. P. Levi: Los hundidos..., op. cit., p. 122; J. Améry: Op. cit., p. 15-36; S. Wiesenthal: Recht, nicht Rache. Erinnerungen. Fráncfort/Berlín ${ }^{2}$ 1988, 430, 433. Cfr. también C. Lanzmann: «The Obscenity of Understanding: An Evening with Claude Lanzmann», en: C. Caruth (ed.): Trauma: Explorations in Memory. Baltimor 1995, p. 178.

${ }^{39}$ Es el término acuñado por R. Antelme en $L ' E s$ péce Humaine Paris 1947.

${ }^{40}$ Cfr. el testimonio de Simon Srebnik en: C. Lanzmann: Shoah. Düsseldorf 1986 (orig. fr. 1985), p. 20s.

${ }^{41}$ Th.W. Adorno: «Aufzeichnungen zu Kafka», en: Gesammelte Schriften 10, Fráncfort 1977, p. 273

${ }^{42}$ Cfr. Z. Ryn -S. Klodzinski: An der Grenze zwischen Leben und Tod. Eine Studie über die Erscheinung des "Muselmann" im Konzentrationslager. Auschwitz-Hefte, Vol. 1, Weinheim/Basilea 1987.

${ }^{43}$ G. Agamben: Op. cit., p. 41-89.

${ }^{44}$ Cfr. E. Wiesel: Macht Gebete aus meinen Geschichten. Friburgo 1986, p. 20ss.

${ }^{45}$ Cfr. P. Levi: Op. cit., p. 11s.

${ }^{46}$ Cfr. A. Wieviorka: «Indecible ou inaudible? La déportation: premiers récits (1944-1947), en: Pardès (1989) 9/10, p. 24.

${ }^{47} \mathrm{E}$. Wiesel llega a afirmar que él no ha escrito de su pasado para que el lector lo conozca, sino para sepa que jamas llegará a conocerlo, cfr. E. Wiesel: Op. cit., p. 22 s. 
${ }_{48}$ Quizás la frase más desenmascaradora de toda comunicabilidad precipitada e ignorante de la absoluta extrañeza de lo testimoniado es la pronunciada por Itzhar Zuckermann en el film Shoah: «Si usted pudiera lamer mi corazón se envenenaría» (C. Lanzmann: $O p$. cit., p. 260).

${ }^{49}$ E. Wiesel: «Die politisch-moralische Aufgabe des Schriftstellers heute», en: O. Schwencke (ed.): Erinnerung als Gegenwart. Elie Wiesel in Loccum. Friburgo 1987, p. 112.

${ }_{50}$ Sobre el papel de la narración en la desactivación de la destructividad de los acontecimientos que irrumpen en el orden del mundo de la vida y también sobre su papel en el aseguramiento de la identidad y la continuidad amenazadas, cfr. H. -J. Görtz: «Erzählen vom Unsagbaren», en: Philosophisches Jahrbuch 93 (1986), 301-307. Cfr. también D. Diener: «Gestaute Zeit Massenvernichtung und jüdische Erzähltstruktur», en: S. Weigel -B. R. Erdle (eds.): Fünfzig Jahre danach. Zur Nachgeschichte des Nationalsozialismus. Zürich 1996, p. 3-15, quien afirma que "Auschwitz" se resiste a la estructura narrativa porque «el troquelado fabril de millones de historias de vida en un uniforme destino letal arrebata al acontecimiento en la conciencia superviviente cualquier estructura narrativa» (p. 5).

${ }^{51}$ Cfr. C. Caruth: «Introduction: Trauma and Experience», en: C. Caruth (ed.): Trauma: Explorations in Memory. Baltimor 1995, p. 3-12.

${ }^{52}$ Cfr. C. Caruth: «Introduction: Recapturing the Past», en: C. Caruth (ed.): Op. cit., p. 151-157.

${ }^{53}$ Cfr. F. Lyotard: Heidegger und "die Juden", op. cit.,. p. 27.

${ }^{54}$ L. L. Langer: Admitting the Holocaust: Collected Essays. Nueva York/Oxford 1995, p.17.

${ }_{55}$ Cfr. Ilan Avisar: Screening the Holocaust: Cinema's Images of the Unimaginable. Bloomington 1988, p. 34 s., $130 \mathrm{~s}$.

${ }^{56}$ Cfr. J. -F. Lyotard: La Diferencia. Barcelona 1988, p. 106ss.

${ }^{57}$ L. L. Langer: Holocaust Testimonies: The Ruins of Memory. New Haven 1991, p. 39.

${ }^{58}$ Cfr. D. Laub: «Bearing Witness, or the Vicissitudes of Listening», en: D. Laub/Sh. Felmn (eds.): Testimoniy: Crises of Witnessing in Literature, Psychoanalysis and History. Londres/Nueva York 1992, p. 204-224.

${ }^{59}$ Cfr. D. La Capra: Representing the Holocaust: History, Theory, Trauma. Ithaca/Nueva York 1994, p.198.

${ }^{60}$ G. H. Hartmann: «Shoah and Intellectual Witness», en: Partisan Rewiev, Otoño 1998, p. 48.

${ }^{61}$ Cfr. L.L. Langer: Holocaust Testimonies..., Op cit., Id.: Preempting the Holocaust. New Haven 1998.

${ }^{62}$ D. Claussen: «Veränderte Vergangenheit. Über das Verschwinden von Auschwitz», en: Shoah Formen der Erinnerung, op. cit., p. 78.

${ }^{63}$ Op. cit., p. 87.
${ }^{64}$ J. Baudrillard: La transparencia del mal. Ensayo sobre los fenómenos extremos. Barcelona ${ }^{4} 1997$ (orig. fr., 1990)., p. 19.

${ }^{65}$ Sobre la discusión en torno a la representación de "Auschwitz" en los diferentes géneros cinematográficos, cfr. I. Avisar: Screening the Holocaust: Cinema's Images of the Unimaginable. Bloomington 1988.

${ }_{66}$ Wilhelm Roth ha mostrado como casi toda la documentación fílmica de los bombardeos sobre Londres fue escenificada y que incluso en otros lugares se hicieron remakes de las trincheras, porque las tomas de las luchas reales no habían salido (Id.: Der Dokumentarfilm seit 1960. Munich/Lucerna 1982, cit. por J. Jochimsen: "Nur was nicht aufhört, weh zu thun, bleibt im Gedächtnis". Die Shoah im Dokumentarfilm», en: Shoah - Formen der Erinnerung, op. cit., p. 219).

${ }^{67}$ I. Avisar: Op. cit., p. 35.

${ }_{68}$ No faltan las valoraciones positivas de esta transgresión, cfr. Y. Loshitzky: «Holocaust Others. Spielberg's Schindler's List versus Lanzmann's Shoah, en. Id. (ed.): Spielberg's Holocaust. Bloomington -Indianapolis 1997, p. 104-118. La cuestión no es si se rompe un tabú, sino la forma de hacerlo y su legitimidad.

${ }^{69}$ C. Lanzmann: «Ihr sollt nicht weinen. Einspruch gegen 'Schindlers Liste'», en: Frankfurter Allgemeine Zeitung (5.3.1994).

${ }^{70}$ Cfr. S. Felman: «Â l'âge du témoignage», en: M. Deguy (ed.): Au sujet de Shoah - Le film de Claude Lanzmann. Paris 1990, p. 89.

${ }^{71}$ Cfr. G. Koch:«Der Engel des Vergessens und die Black Box der Faktizität. Zum Gedächtniskonstruktion in Claude Lanzmanns Film Shoah», en: Memoria - vergessen und erinnern. Ed. por A. Haverkamp y R. Lachmann. Munich 1993, p. 67-77.

${ }^{72}$ El sentimentalismo en nada acerca a la experiencia de los campos, como manifiesta el testimonio de Abraham Bomba, el peluquero de Treblinca: «Sabe usted, sentir algo allí... Allí eso era imposible, sentir algo o tener una sensación. Imagínese trabajar día y noche entre muertos, entre cadáveres. Ahí desaparecen sus sentimientos, en el sentimiento usted estaba muerto, completamente muerto.» (C. Lanzmann: Shoah., op. cit., p. $157 \mathrm{~s}$.).

${ }^{73}$ Cfr. Shoahana Felman: «The Return of the Voice: Claude Lanzmann's Shoah, en: Sh. Felman y Dori Laub (eds.): Testimony: Crises of Witnessing in Literature, Psychoanalysis, and History. Londres/Nueva York 1992, p. 57-74.

${ }^{74}$ Cfr. G. Koch: Die Einstellung ist die Einstellung. Fráncfort 1992, p. 143-155. 